\title{
The uses of literacy: uma contribução autobiográfica para a sociologia
}

\section{The uses of literacy: an autobiographical contribution to Sociology}

HOGGART, R. La culture du pauvre. Étude sur le style de vie des classes populaires en Anglaterre. Les Editions de Minuit: Paris, 1970.

\section{Rosa Maria Bortolotti de Camargo ${ }^{1}$}

The Uses of Literacy, intitulada em português como "As utilizações da cultura2" foi escrita originalmente em 1957 pelo escritor inglês Richard Hoggart. Sua obra fundamentalmente estruturada sob um aporte autobiográfico consegue trazer à tona inúmeros detalhes sobre a vida da classe operária inglesa dos anos 50 realizando um diálogo entre a experiência pessoal e as condições e formas de vida que essencialmente caracterizavam a classe operária popular na época supracitada.

Advindo de uma família e de um bairro popular obreiro da Inglaterra, Hoggart buscou desmistificar a ideia de que exista um pobre romantizado. Passeron (1970), ao apresentar a obra, alude que muitos dos intelectuais da época jogavam entre eles quando se tratava de descrever a imagem das classes populares bem como as suas condições de vida as quais na maioria dos casos, eram vistas e classificadas como negativas pela desapropriação cultural. Contudo, essa mesma imagem se constituía como um objeto simbólico privilegiado para tais grupos intelectuais pois a função deles de reproduzir e produzir uma imagem sobre uma determinada cultura alimentava seus egos enquanto pesquisadores. No caso de The Uses of Literacy, o sociólogo a define como uma obra que apresenta um novo modelo de pesquisa longe daquilo que ele menciona como sendo "burocratas da empiria" (p. 10, tradução nossa') ou da tentação do culturalismo em que se tinha um exagero de elaborações de estatísticas e questionários em que o objetivo

\footnotetext{
${ }^{1}$ Mestranda em Educação do Programa de Pós-Graduação em Educação (PPGE), da Universidade Federal de Santa Maria. E-mail: rosabortolottti@gmail.com

${ }^{2}$ Para esta resenha, utilizou-se a obra na versão francesa intitulada La culture du pauvre. Étude sur le style de vie des classes populaires en Angleterre. Tradução de François et Jean-Claude Garcias, de JeanClaude Passeron e com apresentação de Jean-Claude Passeron (1970). Por isso, algumas traduções de títulos aparecerão de forma literal, seguidos de uma nota de fim com a tradução e a página do capítulo bem como, se necessário, uma nota de rodapé com uma explicação expressão utilizada a fim de situar o leitor.
} 
era desenvolver e apresentar esquemas e gráficos que comprovassem suas análises e opiniões sobre as culturas.

Ainda assim, mesmo que a obra possa ser questionada por falar de uma experiência autobiográfica, pois, segundo o Passeron (p. 11, tradução nossaii) “(...) é verdade que uma experiência autobiográfica não se constitui por si um protocolo de observação metodológica e que um material documentário não poderia - se sugestivo fosse - ser confundido com um conjunto de coordenadas de feitos etnográficos. (...)". Ela traz consigo marcas que se constituem fundamentais em uma caminhada etnográfica, o autor detalha: apresentação clara e concisa organização do espaço e dos lugares de vida dos sujeitos, itinerários e movimentos sazonais ou semanais lineares, ritmos ou espaços de trabalho e de lazer bem declarados, idades da vida e relação entre os sexos ou as gerações que se encaixam, estrutura da constelação familiar e da educação das crianças bem definida, articulação de práticas econômicas e de práticas culturais ou religiosas e a cultura popular, descrição de um repertório de objetos, materiais e de bens de consumo ao mesmo tempo a descrição dos modelos que comandam a utilização destes relacionando-os meticulosamente com os diferentes tipos de atividades da vida cotidiana são alguns exemplos. Segundo Passeron (1970), Hoggart consegue descrever tudo aquilo que um sociólogo ou um pesquisador etnográfico consegue melhor tirar de um bom informante numa pesquisa modelo empírico.

Se as análises do autor podem não parecer originais à primeira vista, o fato de que sua origem social é de uma família pobre, de uma mãe viúva em que ele precisou a vida toda ser bolsista até ingressar na universidade e vir a ser pesquisador fez com que ele ocupasse um lugar favorável para perceber as significações que são atribuídas ao meio social popular e o contraponto com a realidade de fato. Ele consegue, portanto, nas palavras de Passeron (1970) desmascarar o etnocentrismo burguês ou da pequena burguesia e suas interpretações sobre a classe popular que, na maioria dos casos, a determina como aquela que se absorve do que é fundamentalmente fútil na sociedade, que acredita nas medias, que segue as tendências.

The Usages of Literacy aborda detalhadamente o modo de vida da classe popular operária e obreira inglesa dos anos 50 , crenças, pensamentos, filosofias e formas de 
viver que mesmo sendo alguns já ultrapassados outros ainda podemos vivenciar e observar na linguagem da cultura popular atual. É, portanto, uma obra de referência para a introdução dos modelos de escritas etnográficas em pesquisas no campo da sociologia e da cultura pois consegue na descrição dos mínimos detalhes do entorno popular dialogar com diversos conceitos e textos sociológicos. Mais que isso, a leitura da obra coincide como sendo uma reflexão autosociológica do pesquisador e autor na qual nós, enquanto leitores, podemos tomar como referência para refletir sobre nossas próprias experiências pessoais com nossas origens culturais sendo elas populares ou não.

\section{Espaços, tempos e cultura: uma obra dialética}

Para poder da conta de clarificar todo o esquema de pensar das pessoas da classe popular, Hoggart organiza sua obra em duas grandes partes: O anciano tempoiii e As tradições e a tradição ao novoiv. Na primeira, o autor nos apresenta os principais papéis sociais dos sujeitos e espaços que viviam as pessoas das classes populares das primeiras gerações de bairros populares na Inglaterra. Na segunda, as adaptações e transformações que ocorrem no pensamento tradicional ao se entrar no mundo social moderno.

Considerando a divisão proposta pelo autor, entende-se que um dos valores aprendidos com a leitura da obra é o de utilizar os exemplos de Hoggart como uma forma de análise de nossas próprias enquetes investigativas. As pessoas do meio popular não são meros sujeitos de uma pesquisa sociológica, mas, antes de tudo, pessoas que possuem um papel social extremamente importante e imbricado nas relações sociais no espaço que vivem. Fato reconhecido por Passeron (1970), já na introdução, quando afirma que a particularidade do autor é justamente a de transbordar simplicidade nos detalhes, mas, ao mesmo tempo, trazer à tona uma veracidade de formas e feitos que na maioria das vezes passa longe do que os sociólogos universitários, especialistas ou os intelectuais populistas descrevem como classe popular ou sujeitos populares.

A crítica de Passeron (1970) ainda é válida para os dias de hoje e serve de reflexão sobre o papel que nós, investigadores nas diversas vertentes da sociologia ainda devemos desenvolver em nossas pesquisas. Assombrados por uma política de resultados e produção que vem se estruturando nas universidades brasileiras a leitura da obra 
de Hoggart (1970) serve de referência para nos reencontramos ao que essencialmente faz parte das pesquisas nas áreas das humanas e ciências sociais: o reconhecimento de que o terreno de investigação, nossos sujeitos de pesquisas, suas respostas e ações não são números e futuros gráficos, mas representam um processo histórico-social.

A evolução das ações desenvolvidas pelos membros das classes populares é fruto de processos históricos que são marcados, sobretudo, pela acessão e imposição do capitalismo e do consumismo que levou e, ainda leva, a perda de sentidos nas identidades sociais das pessoas, das famílias. E tal processo ganha em notoriedade e claridade quando deixamos de lado o etnocentrismo investigativo e damos o protagonismo da investigação aos sujeitos investigados como fez 0 autor.

Considerando as análises de Cunha (2014), sobre a obra de Hoggart (1970), compreende-se que, na primeira parte, ou seja, o anciano tempo, as classes populares pareciam ter uma autenticidade que Ihes era própria (forma e organização das casas, modos de vida, tipos de relações com os vizinhos e o bairro), mas, a entrada do mundo moderno e do capitalismo trouxeram consigo a fragilidade das relações e dos modos de vida populares reproduzidos até então. $\mathrm{O}$ autor ainda reflete que se a entrada no mundo moderno e do consumo representava o fim dos modos de vida tradicionais da classe popular. Tal mundo era, paradoxalmente, marca da democracia, pois o acesso às medias, as canções, à escolarização, a popularização dos gostos nutria a forma tanto como as famílias e os membros populares atuariam como, também, como agiriam os meios de dominação.

O paradoxo da modernização e democratização é conhecido dos estudos sociais sobretudo quando a análise se dá nos meios populares: ora, mais acesso às informações, formas de vida, qualidade de vida, medias, tecnologias é fundamental para as pessoas das classes populares. Contudo a democratização destes elementos supracitados e tantos outros vem sendo proposta partir de um viés capitalista, consumista e massificante. Critérios que dificultam uma análise crítica das pessoas de meios populares sobre o valor emancipatório que o acesso ao mundo moderno proporciona (ria).

Um exemplo clássico, tomando como referência Charlot (2013), é o da democratização da escola pública para os meios populares seja no Brasil como em diversos outros 
países do mundo. Ou seja, uma democratização permeada por contradições, em que ao se democratizar a educação pública e validá-la como um direito o que se introjeta é a ideia da mudança social através da escola. Portanto, hábitos e formas de pensar tradicionais e ancianos como "a escola não serve o importante é ter uma profissão" são substituídos por uma crença "que sem estudos não somos nada".

Não obstante, o estudo ofertado, a qualidade das relações escolares, o empenho dos alunos nas instituições públicas não acompanha os critérios e níveis de desenvolvimento das classes médias e da burguesia. Logo, a educação pública ofertada nos meios populares, ainda que democrática, se transforma em uma educação dotada de arranjos, de substituições, abreviações, poréns e limites. A crença nos dos alunos e famílias das classes populares também não está voltada ao que se faz, se deve fazer ou como se deve estar na escola para se obter o sucesso social via a educação, como ocorre nas classes médias e na burguesia, mas de que basta estar na escola, ter (consumir) o diploma que o sucesso estará garantido.

Segundo Gomes (2000, p.1), Hoggart (1970) mostra como a classe popular consegue criar [...] em seu encontro com os processos de industrialização e urbanização, formas culturais específicas e, ao fazê-lo, mostrou que a produção e o consumo culturais expressam as relações sociais básicas, as formas de vida de uma dada sociedade [...] e que, portanto, [...] a vida material e a vida cultural estão profundamente interligadas [...] (Gomes, 2000, loc.cit.).

A partir de tais reflexões, pode-se afirmar que atualmente a obra é metodologicamente e sociologicamente importante para a formação de um atual pesquisador em ciência humanas e sociais, sobretudo, no contexto brasileiro. Sendo assim, o próximo o excerto deste resumo destina-se a uma descrição dos capítulos da obra bem como algumas reflexões sobre.

\section{Da decoração dos personagens ao mundo moderno: os capítulos da obra}

No primeiro capítulo, As classes populares ${ }^{\vee}$, o autor situa o perfil de classe popular que faz parte de sua obra. Se tratava, portanto, de famílias terceira e segunda geração dos campesinos ingleses que migraram para a área urbana, constituídas de filhos, tios 
obreiros que trabalham nas indústrias, fábricas e usinas da época dedicando suas vidas para o trabalhado e o sustento de suas casas. Eram moradores de bairros e residências próximas das fábricas em que trabalhavam, com comércio local, casas pequenas grudadas entre si faziam parte do cenário.

No segundo capítulo, o autor apresenta A decoração e os personagens ${ }^{\text {vi }}$ dos espaços populares. Os personagens são a mãe e o pai e a decoração a tradição oral, a casa e o bairro. Cada um destes elementos possui um papel essencial para a vida das classes populares. A mãe é vista como aquela que "(...) ocupa em efeito uma posição central na constelação familiar, pois a que gera a vida dentro da casa, é a que coordena o orçamento familiar (...)" (p.75, tradução nossavii), que faz o mercado, que organiza as questões administrativas que o pai, o qual trabalha o dia inteiro, não pode se ocupar. É a jovem que ao fim dos estudos se casou, sabendo, que seu destino era o doméstico, do lar, a que se abstém dos prazeres para dar o conforto aos seus filhos para eles possam crescer felizes antes de entrarem ao mundo duro do trabalho ou do casamento e dar o conforto ao marido que trabalha o dia todo para manter o sustento financeiro da casa. O pai "(...) constitui a ligação principal entre a casa e o mundo exterior porque ele é aquele que traz o dinheiro para a casa. (...)" (p. 92, tradução nossaviii), é o homem dotado de privilégios, criado numa cultura machista que o destinou a vir a ser marido, "um bom marido", ou seja, aquele que trabalha, que não tem o vício do álcool, que tem sempre dinheiro no bolso e que entrega para a sua mulher, no começo do cada mês, o dinheiro necessário, às vezes apertado, para garantir o sustento da família. A casa é o espaço do encontro familiar em que se deve preservar as boas relações domésticas e sociais. A frase "faz como se fosse sua casa" representa a premissa de que as casas de meio popular devem ser sinônimos das boas relações familiares e também as sociais. No âmbito social, a casa deve ser um espaço que não incomode o vizinho ao lado, ser bom vizinho é aquele quem são sai e entra várias vezes, é fazer uma grande faxina na casa todas as semanas. Contudo, ainda que haja uma iniciativa de manter uma boa relação com a vizinha o importante é proteger e fechar o grupo familiar da própria vizinhança. Hoggart (p. 66-67, tradução nossaix) descreve: “(...) a gente sabe que os vizinhos são gente como você e eu, prontos a nos ajudar se é necessário, mas gente sabe também todas as fofocas, escândalos ou os ridículos que dizem respeito à vida do outro. Uma 
questão governa a grande parte dos atos dentro do contexto familiar: O que os vizinhos vão pensar? (...)". Portanto, no âmbito familiar, a casa é o espaço de proteção, de união entre os membros que juntos se protegem e vivem. O bairro é o espaço físico que estimula o sentimento de pertencimento nas famílias. Muitas famílias habitaram a mesma casa no mesmo bairro durante toda a sua vida. Muitas famílias são o desmembramento da segunda ou da primeira geração de pessoas que foram habitar no bairro. O bairro está próximo das usinas, das fábricas em que se trabalha, a rotina do bairro funciona em função da rotina das famílias e do trabalho dos obreiros nas fábricas. Por fim, a tradição oral, primeiro aspecto apontado pelo autor, diz respeito à linguagem popular dotada de crenças e ensinamentos os quais regem a forma de pensar e viver nos meios populares. A tradição oral carrega tudo aquilo que as pessoas das classes populares acreditam e que paradoxalmente elas reconhecem como sendo como uma tradição oral, mas que, na maioria dos casos, as auxiliam a compreender e entender os momentos desafortunados da vida. São os jargões clássicos, as superstições.

No terceiro capítulo, "Eles" e "Nós"x, Hoggart (p. 117, tradução nossa ${ }^{\mathrm{xi}}$ ) começa afirmando que "(...) a maior parte dos grupos sociais devem o essencial de suas coesões aos seus poderes de exclusão, quer dizer ao sentimento de diferença sobre aqueles que não são "nós" (...)". Efetivamente o sentimento de exclusão entre classes não é um mérito da classe popular visto que estudos referentes a forma como a burguesia e a classe média atuam também revelam o mesmo pensamento coletivo ${ }^{3}$. Sem embargo, tal sentimento é reforçado por aquilo que o autor diz uma certa desconfiança e sentimento de amor próprio.

O mundo "dos outros" é um mundo desconhecido, cheio de pessoas (médicos, responsáveis pela assistência social, as pessoas ricas, o patrão, etc.) que são vistos como pessoas que "de todos os modos ir ao médico, consultar as esferas públicas ou pessoas públicas não muda nada pois estes nunca são claros”. Os outros são aqueles que sempre irão ter uma vantagem, seja nos atendimentos públicos, assistências sociais ou na vida com respeito a "nós". E é, nesse sentido, que a desconfiança sobre os "eles" faz simultaneamente emergir o sentimento de amor próprio dentro dos membros das

\footnotetext{
${ }^{3}$ Ver a obra de Béatrix (1988) Le Wita Ni vue, ni connue. Un approche ethnographique de la culture bourgeoise.
} 
classes populares, o sentimento de que existe uns "nós". O sentimento de que "eu devo me virar sozinho" se enaltece e faz com que os membros das classes populares busquem sempre eles mesmos resolverem seus problemas e evitem as instituições públicas, as ajudas que sejam externas aos seus meios sociais, fortalecendo o pertencimento ao grupo, o sentimento de que "estamos todos no mesmo barco", "a união faz a força" e é por isso que "nós" somos assim... Ainda assim, esse pertencimento ao grupo não é o suficiente para mobilizar uma consciência de classe crítica e mobilizadora, ao contrário, a sensação exagerada do pertencimento isola os membros das classes populares e os fazem lutarem por eles mesmos, dia após dia e não há abertura para um encontro de coesão e luta política entre eles.

O capítulo precedente, O realismo e a realidade cotidianaxii, descreve os interesses das classes populares em estabelecerem as conexões, o gosto pelas coisas a partir daquilo que seja real, tal como é a vida de um trabalhador popular. Paradoxalmente, o membro da classe popular vai frequentar a igreja, mas sua crença estabelece limites na medida em que a religião se afasta da forma de vida deles, vai-se à igreja, mas não se deixa de acreditar nas crenças supersticiosas que fornecem respostas aos contratempos da vida, e, afinal, o padre também faz parte do grupo "nós". No futebol, os homens vão se interessar pelos jogadores que são combatentes, fortes e ao mesmo tempo irão ver o juiz como um intelectual do futebol (como um diretor de escola que chega para acabar com o jogo na hora da recreação impedindo os meninos de jogarem) que não deixa o jogo se desenvolver, que impede o jogador de jogar a bola. O jogador é, portanto, o feito real no passo que o juiz está no plano das ideias e da intelectualidade que impede a execução da realidade. Nas revistas, as mulheres não irão se interessar por coisas fúteis da realeza inglesa mas terão interesse se a notícia de tratar sobre alguma dificuldade ou situação que ocorreu com alguém da realeza e que essa situação seja capaz de mostrar que, apesar de tudo, "eles são gente como a gente".

No quinto, A boa vida ${ }^{\text {xiii }}$, Hoggart detalha a forma como as pessoas das classes populares interpretam os passares dos dias e a forma como o cotidiano é interpretado e vivido pelas pessoas. Basicamente, se refere ao feito de que há uma forma de pensar que se baseia na ideia de é preciso viver a vida, diante da imprevisibilidade do amanhã. "A vida não é um leito de rosas" (p. 183, tradução nossa ${ }^{\text {xiv }}$ ) portanto, se tem que apro- 
veitar um dia após o outro. A crença na sorte e no destino se complementam tal pensar, pois eles são as esperanças que carregam as pessoas da classe popular sobre a própria forma de viver o cotidiano, ou seja, se tivermos sorte e com fé no que o destino nos guarda sobreviveremos, teremos bons dias. Essa forma de pensar é também materializada através da ideia de como as pessoas organizam os orçamentos familiares. $\mathrm{O}$ autor afirma que justamente a ideia de que deve se viver o dia após o outro e a crença na sorte faz com que as pessoas se organizem economicamente pensando sempre utilizar seus dinheiros, comprarem a comida e tudo que é necessário para o bem viver sem investir em poupança, fazer economias. Dar uma boa roupa ou brinquedo para seu filho nas datas comemorativas é garantir a felicidade momentânea que logo acabará quando este filho crescer e entrar no mundo do trabalho, dos sacrifícios do dia-a-dia.

Neste capítulo, o autor ainda fala da decoração das casas, nas quais os membros das classes populares buscam criar/organizar um lar aconchegante que chegue o mas próximo dos modelos e decoração da burguesia. Segundo o autor, se trata de uma decoração barroca, ou seja, um modelo de arte decorativa em formato irregular. O gosto pela música é levantado em um último subcapítulo mencionando o interesse dos membros das classes populares pelas antigas cantigas, advindos de uma sensação de pertencimento às canções que podemos assim chamar de parlendas, canções contadas que tem sempre no fundo uma história, uma interpretação. $\mathrm{O}$ autor menciona diversos exemplos de músicas, de letras e grupos de cantores, mas, ao fim, o que o autor nos remente a pensar é de que as mais preferidas são aquelas capazes de fornecer uma tradução do cotidiano, da vida, canções que possam o quanto antes estabelecer uma relação de pertencimento dos ouvintes com a letra.

Na segunda grande parte da obra, As tradições e a tradição ao novo, Hoggart começa refletindo sobre as mudanças de atitude, gostos ao passar dos anos. Segundo o autor, no capítulo seis, Um materialismo honesto ${ }^{\mathrm{xv}}$, as mudanças se operam gradualmente e se manifestam em níveis diferentes nos diversos domínios da vida social. Em toda situação de mudança os indivíduos tendem a reagir se conectando com diversos sistemas de valores. Assim, mesmo que com o passar dos anos a forma de pensar e atuar em sociedade tenha mudado, em todas as classes sociais, essas mudanças são superficiais pois o sistema de valores que operava sobre o pensar ainda será o mesmo. 
É assim que do capítulo seis até o dez Hoggart especializa sua leitura trazendo elementos da primeira parte e, revelando, como eles operam no contexto atual da época que o livro foi escrito.

No campo das tradições, explica que se as ideias novas, os novos modelos de vida, de pensar, de trabalho, do campo político, literário mudaram a configuração do meio urbano, da vida, as ideias básicas da tradição restam imbricadas no pensar e um sistema complexo de comportamentos clichês passa a fazer parte dos membros das classes populares como uma forma de adaptação ao que, justamente, é exterior a eles. Logo, pode-se dizer que existe, nas classes populares, uma aceitação do mundo, imposto principalmente pelas mídias, mas que não atua diretamente no sistema de pensar, mas no sistema de viver cotidianamente. Expressões como "hoje, todo mundo faz assim" ou "as coisas não são como antigamente" demonstram um sistema de aceitação, mas que não implica num sistema de mudança de cultura de classe.

No campo literário, explicado no capítulo sete intitulado Convite ao romance ${ }^{x v i}$, o autor trata de mostrar as formas como a literatura popular, as revistas e jornais semanais tratam de organizar seus exemplares se estruturando a partir de um modelo padrão que visa não ser custoso na matéria de fabricação e no objetivo nas informações transmitidas: uma página esportiva, uma entrada futurista, invitação à cursos, fórmulas milagrosas para o bem estar (como ficar menos estressado, como parar de fumar...) e uma imagem feminina que mesmo não sendo pornográfica, podendo ser, incita ao prazer, chama atenção à provocação sexual, histórias de policiais, mistérios e ficções científicas fazem parte do conjunto. Se no passado tais escritos eram mais escondidos ou moderamos pela moralidade, na atualidade, Hoggart introduz no capítulo oito, Do sexo sobre o celofane ${ }^{x v i i}$, uma perda total da moral, pelos escritores que se remetem ao meio popular, em que estes tratam de elaborarem suas escrituras da forma mais descritível possível nas ações das histórias a fim de conseguir aguçar o sentimento da angústia, de nervosidade os quais possam causar efeito diretos nos sentidos do leitor. O sexo passa a ser uma forma de venda e que é apreciado, se não se fala de sexo em casa se vê o sexo e as várias instigações ao desejo, uma busca por colocá-lo na realidade das histórias literárias, ou seja, um sexo estampado nas revistas, livros e jornais. 
No penúltimo capítulo, traduzido literalmente como O "Eu não me importo"xviii, Hoggart apresenta um conjunto de expressões e formas de interação social que remetem ao modelo tradicional de pensar a dicotomização de "nós e eles". O autor utiliza os termos ceticismo e cinismo para metaforizar tal proteção, dos membros das classes populares, ao mundo exterior em que um cinismo superficial e o ceticismo mascarado fazem parte da linguagem popular. Se antigamente não se levava a sério recomendações oficiais, tais como a indicação médica e as proposições políticas, por exemplo, atualmente continuam-se não se tomando ao pé da letra as recomendações externas à vizinhança e ao entorno popular porque tem-se no inconsciente que de todos os modos as morais, os valores, as sugestões não querem dizer nada. Se aceitamos as imposições das mídias, é porque hoje elas funcionam assim, não levamos as recomendações a sério pois sabemos que por detrás há um governo, de um patrão, um alguém que não faz parte de nosso mundo, obreiro, popular.

No último capítulo, Desraizados e Desclassificados ${ }^{\text {xix }}$, Hoggart estimula sua escrita em torno daqueles membros das classes populares que de uma forma ou de outra se direcionaram para o "mundo dos outros". Aqueles que por uma razão acabaram se distanciando da classe popular e se direcionando para os modos de vida de uma classe superior. Primeiro exemplo, seriam os bolsistas, ou seja, aqueles jovens que tendo uma bolsa para estudos deviam ser obedientes e bons alunos na escola.O autor desenvolve que todo o estudante que graças a um sistema de bolsas consegue realizar grandes estudos, por exemplo terminar o estudo universitário, é conduzido para um conflito entre seu mundo familiar, do bairro e seu mundo escolar. O que se aprende na escola não se aprende em casa, o que se aprende em casa não tem espaço na escola. Atuando entre os dois mundos, o bolsista acaba sendo aquele que não desfruta de maior tempo fora de casa, com seus amigos do bairro, aquele que não vai desfrutar de uma vida sexual precoce, mas, ao contrário, será aquele que está mais conectado com o mundo interior e feminino da casa, ou seja sempre dentro de casa com sua mãe e irmãs.

Eles aprenderão a dominar os conteúdos escolares para conseguirem destaque na escola, vão ficar sempre afastados do cotidiano popular, espirarão uma profissão longe da usina e ocuparão um cargo em uma empresa de hierarquias. Como souberam durante toda a vida escolar respeitar a autoridade do professor, irão transpor tal respeito 
ao seu chefe e patrão. Ou seja, “(...) pagando seus estudos com sua inteligência e tendo rápido remarcado que, no mundo moderno, os diplomas se tornam cada vez mais pagantes (...)" (p. 353, tradução nossa ${ }^{\mathrm{xx}}$ ) o bolsista leva seus estudos muito a sério. O autor ainda agrega que a vida para o bolsista “(...) é uma escala sem fim, como um gigantesco sistema de exames em repetição em que cada etapa é marcada por felicitações e "de" exortações a visualizar cada vez mais altas (...xxi)" (p. 353, tradução nossa).

Contrariamente ao bolsista que consegue estabelecer uma relação entre o mundo escolar, cultural e popular, tendo uma boa relação com seus membros familiares e com a comunidade que vive o autodidata é o segundo exemplo exposto pelo autor, mas, é aquele que conseguindo obter conhecimentos para além do senso comum do seu grupo social, recusa suas origens, possui vergonha de sua classe e tem a tendência a ver os membros populares desde alto. Paradoxalmente, ele não se sente bem dentro do meio burguês e rico pois não se visualiza fazendo parte. O autodidata é aquele que está no vazio social, não será integrado com seus companheiros da sua classe de origem, pois nem mesmos eles o aceitam da forma como atua, nem será integrado na classe burguesa e rica pois não possui segurança em si mesmo para adotar um papel burguês. Por fim, há as revistas e manuais de formação cultural, que prometem transformar sua forma de viver e seus hábitos, formas de leituras direcionadas para aqueles que estão insatisfeitos com suas inércias culturais nutrem as livrarias populares vendendo a fórmula do homem moderno.

The Uses of Literacy é uma obra completa, por vezes densa e pessimista, e seguramente com algumas formas, expressões, métodos de análise que não coincidem com a atualidade das classes populares e nem mesmo da organização da sociedade. Não obstante, a obra não deixa de nos enriquecer sociologicamente e metodologicamente pois consegue, através da descrição detalhada do meio social, dos mecanismos de interação entre os sujeitos e na descrição do papel social de cada sujeito dentro dos bairros populares nos ensinar muito sobre o pensar o humano, os condicionamentos e as estratégias de pensar que irrigam as ações entre as pessoas.

A obra consegue desmistificar a ideia de que a classe popular por si só seria uma 
consumidora voraz das mídias, dos gostos e dos costumes modernos. Ao contrário, cada vez mais a situação dos jovens populares se restringe, ou seja, ao modelo da constituição familiar via o casamento e o trabalho árduo, mais eles tendenciam a retornarem aos velhos costumes, as tradições, as superstições para conseguirem se não vencer no mundo, encontrar razões que expliquem os contratempos negativos e positivos da vida.

Num último aspecto, The Uses of Literacy nos mostra, que os membros das classes populares, possuem tantos modos de via em comum que se perpetuam e se resinificam até os dias de hoje lhes faltando apenas o elo fortalecedor que poderia contribuir para a garantia de melhores formas de vida, os direitos básicos dentro das esferas pública, ou seja a consciência de classe. Os membros das classes populares, carregados em si do trabalho, da luta pela sobrevivência perecem e se perdem no cotidiano laboral não existindo tempo, nem dinheiro que contribua para a mobilização sindical ou popular. Compreender o cotidiano das classes populares é entender, portanto, que todos aqueles que se encaixam nesse modo de vida possuem limitações sociais que os impedem de irem adiante, mas que ao mesmo tempo não são estimulados pois não existe um sistema de união popular capaz de os fazerem compreender que juntos, além de se ajudarem e se agruparem entre si, poderiam reivindicar melhores formas de vida.

Diversas obras foram produzidas no campo da sociologia em que o modo de desenvolvimento das pesquisas estavam voltadas para os relatos do cotidiano em que as próprias descrições detalhadas dos modos de vida levam o leitor a uma reflexão crítica sobre os processos de mudança social e a consequência no cotidiano, na cultura popular. Alguns exemplos, são: Margaret Mead (1999) com a obra "Sexo e Temperamento", Erving Goffman (1963) em "O estigma: notas sobre a manipulação da identidade”, Pierre Bourdieu et Jean-Claude Passeron (1964 e 1970) com as obras "Os herdeiros: os estudantes e a cultura" e a "A reprodução: elementos para uma teoria de ensino" bem como Pierre-Bourdieu (1997) com a obra, "A miséria do mundo", Roger Establet e Christian Baudelot com a obra "A escola capitalista na França" (1971). Por fim, Bernard Lahire (2012) e a obra "O homem plural: os determinantes da ação".

Muitas destas leituras sociológicas, entre outras não citadas, se inscreviam em um contexto e, mais especificamente, de um ocidente pós-guerra, em que os países eram 
regidos por Estados Desenvolvimentistas (CHARLOT, 2013) nos quais o objetivo era de investir nas indústrias, na mão de obra obreira, na educação técnica e profissionalizante a fim de potencializar a produção de matérias primas e secundárias que fortalecessem a economia do país. Sendo assim, a produção de uma massa populacional obreira, ou seja, trabalhadora era extremamente necessária e estimulada. Ademais, seria a classe popular, também, uma consumidora massiva dos produtos que ela mesma produzia. Logo, os estudos supracitados se direcionavam para desmascarar, justamente, a sociedade da época que era organizada a favor de um status quo que estruturava os papéis dos cidadãos: a vida e a cultura dos trabalhadores, dos obreiros, os estudos dos seus fiIhos, o papel da mulher versus a vida e a cultura da burguesia, do patrão, dos intelectuais e de seus filhos e suas esposas.

O livro de Hoggart, portanto, nos introduz num sistema de pensar que pode contribuir para, quem sabe, os intelectuais orgânicos, a classe política, os professores ou atores educativos que tem seus interesses e discursos voltados para as classes populares consigam entender mais minuciosamente a organização social que os irriga bem como se afastar da imagem romantizada de uma classe popular crítica e consciente, que segundo o autor faz parte de uma minoria nas classes populares, buscando os meios de promover conhecimento e emancipação crítica que coincida com a realidade do povo e não, ao contrário, que se resuma à discursos e jargões populistas. 


\section{Notas}

'Bureaucrates de l'empirie.

iill est vrai qu'une expérience autobiographique ne constitue pas par soi un protocole d'observation méthodologique et qu'un matériel documentaire ne saurait - si suggestif fût-il - être confondu avec un ensemble de coordonné de faits ethnographiques.

iii'Lancien temps (p. 33).

iv Les traditions et la tradition du nouveau (p. 219).

v'Les classes populaires (p. 34)

viLe décor et les personnages (p. 55)

vii (...) occupe en effet une position centrale dans la constellation familiale (...)

viii (...) constitue le lien principal entre e foyer et le monde extérieur parce qu'il est celui qui "rapporte" l'argent à la maison.

${ }^{i x}$ On sait bien que les voisins sont "de gens comme vous et moi", prêts à rendre service si le besoin s'en faisait sentir, mais on sait aussi qu'ils sont à l'affût des commérages et particulièrement friands d'échos scandaleux ou ridicules sur la vie privée des autres. Une question gouverne la plupart des actes : 'Qu'est que les voisins vont penser?".

x "Eux" et "Nous" (p.115) “"

xi La plupart des groupes sociaux doivent l'essentiel de leur cohésion à leur pouvoir d'exclusion, c'est-àdire au sentiment de différence attaché à ceux qui ne sont pas "nous".

xii Le réalisme et la réalité quotidienne (p. 147).

xiii La bonne vie (p. 181).

xiv La vie n'est pas un lit de roses.

xv Un matérialisme honnête (p. 221).

xvi L'invitation à la romance (p.261).

xvii Du sexe sous cellophane (p. 299). Difícil encontrar uma tradução para tal expressão. De forma sucinta se trata da existência de uma literatura erótica que é vendida nas livrarias, nos bares, mas que é tapada, camuflada. Por vezes, uma forma até mesmo hipócrita de dizer que elas existem, todo mundo as lêem, mas elas não são comentadas nos diálogos, nas rodas de conversa.

xviii Le "je m'en-fichisme” (p. 325). Expressão popular originária da expressão "je m'en-fiche”. Quer dizer, "eu não ligo", ou "eu não me importo". No caso do capítulo, se trata da adição do prefixo "isme" o qual qualifica a expressão tornando-a como uma ação que as pessoas adotam no seu modo de vida, ou seja, 
a prática de "não ligar".

xix Déracinés et déclassés (p.345). A tradução literal é a indicada no texto. Contudo, sabe-se que a palavra "desclassificados" pode tomar diferentes interpretações. No caso da escrita, se trata dos indivíduos que estão foram de sua classe social, que não compartilham a mesma forma de vida de sua classe, que realizaram uma mobilidade de classe social mesmo que ela não tenha sido à nível de salário, mas no nível do capital cultural, modo de vida.

xx Payant ses études avec son intelligence et ayant vite remarqué que, dans le monde moderne, les diplômes deviennent de plus en plus "payants"(...)

xxi (...) une échelle sans fin, comme un gigantesque système d'examens à répétition où chaque étape est marquée par des félicitations et des exhortations à viser encore plus haut.

\section{Referências}

BOURDIEU, P. A miséria do mundo. 5a ed. Pétropolis: Editora Vozes, 1997. 747p.

BOURDIEU, P.; PASSERON, J-C. Les héritiers: les étudiants et I aculture. Paris: Les Editions de Minuit, 1964. 192p.

P.; PASSERON, J-C.A reprodução. Elementos para uma teoria do sistema de ensino. 3 ed. Rio de Janeiro: Editora Francisco Alves, 1970. 283p.

CHARLOT, B. Da relação com o saber às práticas educativas. São Paulo: Cortez, 2013.

CUNHA, S. D. Usos e abusos da cultura. Richard Hoggart e a cultura vivida da classe trabalhadora. Comunicação Pública, v.9, n.16, 2014, p.1-11. Disponível em: http://journals.openedition.org/cp/861\#bibliography . Acesso em: 1 mar. 2018.

ESTABLET, R., BAUDELOT, C. L'école capitaliste en France. Paris: François Masperto, 1971. 347p.

GOFFMAN, E. O estigma. Notas sobre a manipulação de uma identidade deteriorada. Rio de Janeiro, Editora LTC: 1963. 124p.

GOMES, M.M.I. The Uses of Literacy: Hoggart e a cultura como expressão dos processos sociais. In: XXIII Congresso Brasileiro de Ciência da Comunicação em Manaus / Comunicação e Recepção. Manaus: 2000. Disponível em: http://www.portcom.intercom.org.br/pesquisa.php . Acesso em: 1 mar. 2018.

HOGGART, R. La culture du pauvre. Étude sur le style de vie des classes populaires en Anglaterre. Les Editions de Minuit: Paris, 1970.

LAHIRE, B.Monde pluriel. Penser l'unité des sciences sociales. Paris: Seuil, 2012. 393p.

MEAD, M. Sexo e Temperamento. 4a ed. São Paulo: Perspectiva, 1999, 316p. 